\title{
CORPORATE GOVERNANCE WHEN MANAGERS SET THEIR OWN PAY*
}

\author{
Pablo Ruiz-Verdú ${ }^{1}$
}

\begin{abstract}
This paper presents a model of the firm in which the manager has discretion over his own compensation, constrained only by the threat of shareholder intervention. The model addresses two questions: How does shareholder power affect managers' compensation and their incentives to maximize firm value? And, which is the optimal level of shareholder power? Increasing shareholder power leads to lower managerial pay, yet it also weakens managers' incentives to maximize value. The model shows that, because of this incentive effect, restricting shareholder power is necessary to obtain financing, and offers predictions about the relation between the optimal level of shareholder power, performance and firm characteristics.
\end{abstract}

Keywords: Executive compensation, corporate governance, shareholder power, managerial discretion over pay.

JEL Classification: G30, D86, L20, M50.

\footnotetext{
* The author would like to thank Sandro Brusco, Marco Celentani, María Gutiérrez, Ravi Singh, Daniel Wolfenzon, and seminar participants at the Econometric Society 2006 European Meetings, the 2005 SAET Conference, and Universidad Carlos III for helpful comments. The usual disclaimer applies. The financial support of Spain's Ministry of Education and Science (SEJ2005-06655/ECON) is gratefully acknowledged.

${ }^{1}$ UniversidadCarlos III de Madrid, Department of Business Administration. Calle Madrid, 126. 28903Getafe, Madrid - Spain. E-mail: pablo.ruiz@uc3m.es.
} 
The historically high level of compensation enjoyed by U.S. executives, together with a series of high-profile scandals, has fueled an intense public debate about executive pay and the need for corporate governance reform. While economists have traditionally viewed executive compensation contracts as an optimal response to the problem of providing incentives to firms' managers, several researchers (Bertrand and Mullainathan, 2001; Bebchuk and Fried, 2004) have recently put forth an alternative view of executive compensation, according to which CEOs effectively set their own pay. In line with this view, critics of current compensation practices - from activist institutional investors to academics - have called for corporate governance reform aimed at increasing shareholders' power over managers and boards of directors.

In this paper, I propose a model of the firm in which the manager has discretion over his own pay. The model addresses two of the main questions that underlie the debate about executive compensation and corporate governance reform. First, how does shareholder power affect managers' compensation and their incentives to maximize firm value? And, second, which is the optimal level of shareholder power?

The model assumes that the board's interests are aligned with those of the manager, with the result that the manager effectively sets his own pay. The manager's ability to extract rents is, however, constrained by the threat of shareholder intervention: even if the board of directors serves the manager's interests, the shareholders of a publicly held corporation can still oust the manager by launching a proxy contest to replace the board. Shareholders' power is, however, limited, since proxy contests face considerable hurdles. Apart from substantial procedural costs, there are freerider problems in all stages of the process, often aggravated by charter provisions (like staggered boards) that add to the difficulty of replacing directors. ${ }^{1}$ In the model, I use the costs of staging a successful proxy contest (which I label control costs) as a measure of shareholder power. Using this measure, I find that greater shareholder power has the expected effect of reducing managerial pay. However, greater shareholder power also weakens the manager's incentives to maximize firm value.

\footnotetext{
${ }^{1}$ See, e.g., Bebchuk (2007) for a description of the costs associated with proxy contests.
} 
This result parallels the ones obtained by Burkart, Gromb, and Panunzi (1997), Pagano and Roell (1998), Almazan and Suarez (2003) and Adams and Ferreira (2007), showing that too much control by shareholders or the board may hurt managerial incentives. This paper, however, highlights a novel mechanism by which shareholder power influences incentives; namely, through the effect that shareholder power has on the relation between managerial pay and firm performance. Key to understanding this mechanism is the fact that shareholders will only intervene when their expected payoff from intervention net of control costs is higher than the return provided by the incumbent manager. Therefore, shareholders will not intervene in states of nature in which expected cash flows are low, since, in those states of nature, control costs exceed the payoff from intervention. This implies that the manager effectively becomes the residual claimant when cash flows are lower than the costs of control, while the relation between cash flows and pay is flatter when cash flows are larger. Lowering the costs of control (that is, increasing shareholder power) reduces the set of states in which the manager is the residual claimant and, therefore, weakens the manager's incentives to maximize firm value.

In a competitive capital market, an entrepreneur seeking outside equity financing for a project will adopt the governance structure that, among those that ensure investors a sufficient return, maximizes the project's net present value. The negative effect of shareholder power on incentives implies that, to achieve the goal of maximizing the project's net present value, the entrepreneur would like to minimize shareholder power. Investors, however, will contribute their funds only if they are assured that they will obtain an adequate level of profits from the entrepreneur. Therefore, to derive the optimal level of shareholder power, it is necessary to understand the effect of shareholder power on profits. This effect is twofold. On the one hand, increasing shareholder power (i.e., decreasing control costs) reduces the manager's expected pay, and, thus, has a positive effect on profits. On the other hand, by weakening the manager's incentives, an increase in shareholder power has the effect of reducing the expected value generated by the firm, and, thus, depresses 
profits. When shareholders wield substantial power, the latter effect may be stronger than the former, so increasing shareholder power has the perverse effect of reducing profits. For lower levels of shareholder power, however, increasing that power unambiguously increases profits. Therefore, a trade off emerges between strengthening managerial incentives - which calls for reducing shareholder power - and securing investors a sufficient return - which requires a high enough level of shareholder power. I show that the level of shareholder power that achieves the optimal trade off between incentives and shareholder return is the minimum among those that guarantee that investors earn their required return. It is, thus, ex ante optimal for the entrepreneur to limit shareholders' power by choosing a governance structure that makes it costly for shareholders to replace him. This result provides an explanation for the fact that firms' governance arrangements do not attempt to minimize control costs even at the IPO stage (Daines and Klausner, 2001; Field and Karpoff, 2002). ${ }^{2}$ I also show that control costs will be greater when the entrepreneur's actions have a large impact on value, when the conflict of interest between shareholders and the manager is moderate, and when the potential net present value of the project is large. Therefore, the model offers potentially testable implications about the determinants of firms' corporate governance structures.

The model also allows us to investigate the equilibrium relation between shareholder power and firm performance. Demsetz (1983) has proposed that there should be no equilibrium relationship between profit rates and the quality of corporate governance if corporate governance arrangements are optimally set. If returns on assets are used as a measure of performance, I find that there is indeed no equilibrium relationship between performance and control costs. If performance is measured in terms of cash flows (gross of managerial compensation) or total surplus, however, the equilibrium relationship between shareholder power and firm performance is negative. That is, firms that optimally require greater shareholder power generate less value.

\footnotetext{
${ }^{2}$ Alternative explanations have been provided by DeAngelo and Rice (1983), Stulz (1988) and Stein (1988), although Daines and Klausner (2001) claim that these explanations cannot explain the observed pattern of anti-takeover provisions in IPO firms. DeAngelo and Rice (1983) and Stulz (1988) propose that anti-takeover provisions may confer the manager a greater bargaining power when negotiating a takeover premium on behalf of the firm's shareholders. Stein (1988) argues that those provisions may prevent managerial myopia induced by the threat of takeover.
} 
The model presented here differs in two essential accounts from usual models of executive compensation. First, while in usual models, compensation is determined by a contract designed by the principal (be it shareholders or a board whose interests are aligned with those of shareholders), in this paper, compensation is effectively determined by the manager. Therefore, the model fills a gap in the literature on executive compensation, in which, despite much discussion about managerial influence over pay, there is little theoretical work that explicitly incorporates that influence. ${ }^{3}$ Hermalin and Weisbach (1998) and Almazan and Suarez (2003) have recently developed models in which the manager's pay is determined through bargaining between the CEO and the board, but the model in this paper is, to my knowledge, the first to formally derive the implications of managerial discretion over pay. ${ }^{4}$ Second, usual executive compensation models generally regard compensation arrangements as complete contingent contracts. This view limits their ability to contribute to the current debate about corporate governance reform, since, as argued by Hart (1995), if "principal-agent contracts are comprehensive, it is hard to find a role for governance structure" (p. 679). ${ }^{5}$ In contrast, I assume that pay is effectively determined ex post. This assumption reflects the fact that actual compensation arrangements are, to a large extent, incomplete, with ample room for ex post determination of pay by the board. Further, it allows us to link executive compensation and governance structure, understood, along the lines of the incomplete contracting approach proposed by Hart (1995) or Zingales (1998), as the set of constraints that shape the ex post bargaining over the quasi-rents generated by the firm. In modeling pay as effectively determined ex post by

\footnotetext{
${ }^{3}$ In his oft-cited review of the executive compensation literature, Murphy (1999) states: "[T]here is no doubt, however, that CEOs and other top managers exert at least some influence on both the level and structure of their pay." The debate among researchers has focused on whether this influence is strong enough to merit a departure from the optimal contracting framework. Thus, Murphy and Zabojnik (2004), Hermalin (2005), or Gabaix and Landier (2006) offer explanations to current trends that do not involve managerial rent extraction. Jensen, Murphy, and Wruck (2004) also provide an explanation based on directors' failure to understand the costs of stock option compensation. In this paper, I contribute to this debate, which should be elucidated empirically, by providing testable implications of managerial discretion over pay.

${ }^{4}$ Recently, Singh (2006) has also developed a model in which reputational concerns by board directors may lead them to design inefficient pay packages for managers.

${ }^{5}$ See, however, Hermalin and Weisbach (2006) for a discussion of governance reform when corporate governance is understood as a set of contracts. Hermalin and Weisbach (2006) consider that, in that context, reforms may translate into greater precision of the signal of managerial performance received by the board, or into greater costs for the manager of concealing information.
} 
the manager, I draw from the work of Fluck $(1998,1999)$ and Myers $(2000)$, who have shown, in a repeated game context, that outside equity financing is sustainable even if performance is not contractible and managers can costlessly divert cash flows.

The paper is organized as follows. The model is introduced in Section 1. The relation between control costs and incentives is analyzed in Section 2, while Section 3 studies the impact of changes in control costs on performance. Section 4 analyzes the firm's financing stage and Section 5 derives the optimal level of control costs. Finally, Section 6 discusses several implications of the model, and Section 7 concludes.

\section{Setup}

Consider a risk-neutral entrepreneur who can undertake an investment project that requires an initial investment of $I$ dollars. To finance this initial investment, the entrepreneur issues equity that is sold to outside investors. By buying the firm's equity shares, investors acquire the right to receive the residual earnings generated by the firm and the right to decide on any of the firm's matters, including the entrepreneur's permanence as manager and his pay. The operation of the firm is, however, delegated to the manager. If the project is financed, the manager makes a strategic decision that determines the profitability of the project. I assume that the firm is liquidated once the project is completed. The stages of the model are described next and summarized in Figure 1:

1. The entrepreneur issues shares, which are offered to a pool of risk-neutral outside investors. If the total amount that investors are willing to pay for the shares, $P_{E}$, is greater than the cost of the project, $I$, the project is financed. For simplicity, it is assumed that the entrepreneur does not retain any ownership share.

2. If the project is financed, the manager chooses an action $a \in A$, where $A=[0, \bar{a}]$. Action $a$ is a strategic decision that determines the profitability of the project. Actions are ordered so that higher values of $a$ correspond to actions that lead to higher expected revenues. Therefore, 
$a$ can be interpreted as a one-dimensional measure of the degree of alignment between the actions taken by the manager and those that would lead to the maximization of the project's revenues. I assume that there is a conflict of interest between the manager and shareholders, so that taking action $a$ has a cost for the manager given by:

$$
\eta(a)=\frac{\alpha a^{2}}{2}
$$

This cost reflects the opportunity cost of dedicating time and effort to the pursuit of profit maximization rather than to other activities that would, other things equal, be preferred by the manager. For example, if we interpret $a$ as the time and effort devoted by the manager to investigating the consequences of the different strategic options available, then $\eta(a)$ would simply reflect the usual cost of effort. Alternatively, we can interpret $a$ as an actual strategic choice, such as the selection of the type of product offered by the firm. The manager may know some markets better or may enjoy working with certain products. Choosing the profitmaximizing product would, thus, have the personal cost for the manager of learning how to operate in a relatively unknown market or of giving up the personal benefits of working with a product that is appealing to the manager. Although $a$ is to be interpreted generally as a measure of the degree of alignment between the actions taken by the manager and those that would be preferred by shareholders, I will often refer to $a$ simply as 'effort' for the sake of brevity. The parameter $\alpha$ in (1) is a measure of the severity of the potential conflict of interest between the manager and shareholders.

3. The action taken by the manager determines the probability distribution of firm revenues $x$. In line with the definition of $a$, it is assumed that revenues (net of all costs except for the manager's compensation) are given by:

$$
x=p a+\epsilon,
$$

where $p$ is a parameter that reflects the importance of the manager's actions. The random 
variable $\epsilon$ is assumed to be distributed normally with mean zero and density $\phi$. It is worth noting that the results do not hinge on the particular specification of the stochastic relation between $a$ and $x$. I employ the functional form specified in (2) because of its intuitive appeal and tractability, but the results can be derived for more general specifications. ${ }^{6}$

4. After $x$ is observed, the manager offers to pay $d$ to shareholders.

5. If shareholders are satisfied with the return offered to them by the manager, they do not intervene. Otherwise, they exercise their control rights, fire the manager and hire a replacement to run the firm under direct owner oversight until the end of the period. Replacing the manager involves costs of control $c$ for shareholders. The replacement is paid a competitively determined salary $\mu$, which I assume, for simplicity, to be zero.

6. Finally, payoffs are distributed among shareholders and the manager. If there is no intervention, the manager's compensation consists of the earnings that remain after paying $d$ to shareholders. If there is intervention, the manager is fired and earns $\mu=0$ elsewhere.
1. Equity issue
3. $a$
5. $d$
7. Payoffs distributed
2. $I$ invested in project
6. Owners decide
whether to intervene

Figure 1: Time line

Throughout the paper, I denote by $\theta \equiv(p, \alpha, I)$ the vector of parameters of the model. I solve the model by backward induction. Thus, I first analyze in Sections 2 and 3 the equilibrium in the subgame that starts after the firm receives financing. Then, I study in Sections 4 and 5 the financing stage. Before proceeding with the equilibrium analysis, however, I discuss some of the model's assumptions in greater detail.

\footnotetext{
${ }^{6}$ In particular, we could consider a general distribution of revenues with associated density $f(x \mid a)$. Assuming that this density satisfies the so-called monotone likelihood ratio property - common in principal-agent models - would be sufficient to derive the main results.
} 


\subsection{Compensation, contracts and managerial discretion over pay}

As discussed in the introduction, the model incorporates two main assumptions that distinguish it from usual models of executive compensation. The first assumption is that it is not possible to write enforceable contingent compensation contracts. Therefore, the manager's pay is not determined ex ante by a contract that makes pay contingent on firm performance, but, instead, is determined ex post, after the manager - and shareholders - observe the firm's revenues. This assumption is motivated by actual practice. First, with the exception of some provisions to be found mainly in executives' employment contracts, compensation arrangements do not take the form of explicit contracts that can be enforced by a court. ${ }^{7}$ Further, compensation plans only loosely characterize the way in which executives are to be rewarded and leave ample room for ex post discretion in the determination of the manager's pay. ${ }^{8}$ The board usually has discretion to set the base salary, and bonus payments and stock option or equity grants are often made contingent on the board's subjective appraisal of the manager's performance. Further, even though objective performance measures are widely used, the board can usually decide which measures to use and how to do so. Boards also have discretion over the timing of stock option grants, which they could strategically use to the advantage of the CEO by, say, granting options before announcing good news about the firm or coinciding with an abnormally low price of the firm's stock (Yermack, 1997). In fact, during the 1990s and 2000s, many firms "backdated" options (Heron and Lie, 2007), that is, they picked as grant date a past date on which the stock price was particularly low. ${ }^{9}$ Boards are also able to

\footnotetext{
${ }^{7}$ Employment contracts often contain provisions regarding entry salaries, joining bonuses and, most often, severance payments. It is worth noting, however, that a large fraction of CEOs do not even have formal employment contracts, but are rather at-will employees of their firms (Schwab and Thomas, 2006).

${ }^{8}$ The following quotes illustrate this point: "Assurant [...] says its compensation committee can adjust incentive payments for extraordinary events, "including, but not limited to, acquisitions or dispositions of businesses, litigation costs, tax or insurance recoveries or settlements, changes to accounting principles, asset impairment and restructuring."” (Morgenson, 2006). "The target for [Home Depot's CEO] had been total shareholder return [...] compared with a peer group, and the company was performing poorly by that measure in 2003, according to the Corporate Library. But that year, the board changed the target to one of growth in average diluted earnings per share." (Creswell, 2006).

${ }^{9}$ Stock options are almost universally granted with an exercise price equal to the price of the stock on the date of the grant. Thus, choosing a date in which the stock price is low increases the manager's expected gains. With backdating, this is achieved with no risk.
} 
adjust their policies to undo the effects of past compensation decisions. For example, after a fall in the stock price, boards can reprice options (although few choose to do so anymore) or replace extant options with new ones with a lower exercise price.

Although the issue will not be investigated here, it is worth noting that, given the complexity of the executive role and the need to retain valuable executives, the incompleteness of executive compensation contracts may well be optimal (Bernheim and Whinston, 1998; Baker, Gibbons, and Murphy, 1994). Further, board directors could use the discretion that this incompleteness grants them to pursue shareholders' interests. As mentioned in the introduction, however, there are good reasons to think that managers' interests play an important role in the process by which managerial compensation is set (see, e.g., Bebchuk and Fried, 2004, ch. 23, for a description of the pay setting process). To study the consequences of managers' influence over the determination of their own pay, I make the extreme assumption that the board actually serves the manager's interests when setting his pay. To capture both ex post pay determination and managerial discretion over pay, I assume that, after the state of nature is realized, the manager decides how much of the revenues to keep and how much to distribute to shareholders. Therefore, the manager's compensation is given by

$$
m(x)=x-d
$$

It is important to note that the assumption of managerial discretion over pay does not mean that the manager has the ability to freely set any compensation contract for himself. Apart from problems of costly contracting that may prevent the writing and enforcement of meaningful compensation contracts, I assume that the very power that allows the manager to determine his pay prevents him from committing to any contract that does not give him the maximum compensation possible in each state of nature. Therefore, in the model, the only possible 'contract' has the form described in (3). 


\subsection{Shareholder Intervention}

Shareholders legally possess the right to control the firm. If the manager, to whom they delegate the exercise of that control, sets an excessive level of compensation, shareholders will reassert their control rights and intervene to secure a sufficient return. Therefore, the manager's ability to set his own compensation is limited by the threat of owner intervention.

The model assumes that if shareholders intervene, they fire the manager and hire a replacement to run the firm under direct owner oversight until the end of the period. In such a case, both the departing manager and his replacement are assumed to earn $\mu$, which can be interpreted as a market-determined entry salary for managers without firm-specific skills. It is also assumed that the key strategic decisions are made by the initial manager and are summarized by $a$. The actions taken by the manager after selecting $a$ are assumed to be day-to-day operating decisions, which have a lesser influence on profits. Therefore, I do not explicitly model those decisions and assume that the revenues generated by the firm are $x=p a+\epsilon$, independently of whether the manager is the initial one or a replacement. ${ }^{10}$ Under this assumption, shareholders' payoff in case of intervention is given by $x-\mu=x$, since I assume, for simplicity, that $\mu=0$.

Although I consider that shareholder intervention takes the form of CEO replacement, other forms of shareholder intervention are possible. Shareholders could try to negotiate a pay reduction with the manager, vote down management-sponsored compensation proposals,${ }^{11}$ or challenge the manager's compensation in court. ${ }^{12}$ The assumption that shareholder intervention takes the form of manager replacement is made mainly for simplicity, and results would not change if we assumed,

\footnotetext{
${ }^{10}$ Revenues could fall after firing the manager if he had acquired firm- or project-specific skills. This can be accounted for in the model if $c$ is interpreted as reflecting not only the direct costs of intervention but also the loss of the manager's specific skills. Since the model is a pure moral hazard model, however, I do not consider the possibility that alternative managers may be of different ability.

${ }^{11}$ Morgan, Poulsen, and Wolf (2006), however, document that - even though the number of negative votes increases over time - of 2,083 management-sponsored compensation proposals corresponding to the period 1992-2003, only eight were voted down by shareholders. Shareholders can also attempt to vote proposals aimed at reducing the manager's compensation. However, these proposals are not binding, so boards can, and routinely do, disregard them.

${ }^{12}$ Bebchuk and Fried (2004), ch. 3, review the obstacles to the success of a lawsuit challenging managers' compensation packages. Citing evidence provided by Barris (1992) that in almost all cases since 1900 involving publicly traded firms, courts have refused to overturn board compensation decisions, Bebchuk and Fried (2004) affirm that "as a practical matter, judicial review fails to impose any constraint on executive pay" (p. 45).
} 
instead, that intervention did not involve replacing the manager, but only reducing his pay down to his reservation salary $\mu .^{13}$

\subsection{Control costs}

Shareholder intervention is not costless. If the board of directors acts in the interest of the manager and not of shareholders, as assumed in the model, the only avenue left to shareholders to replace the manager is to stage a proxy fight to vote a new board of directors. Proxy fights are, however, very expensive and subject to severe free-riding problems. On the one hand, the costs of staging a proxy fight, which are typically very high, are borne by the shareholders who organize it, while the benefits are shared with all shareholders. ${ }^{14}$ On the other hand, there is also a free-riding problem when voting, since the costs of acquiring and processing information about the competing slates are privately borne, while the benefits are shared with all owners.

Therefore, owners will only intervene if the return that the manager grants them lies below the one they would obtain if they intervened, net of the costs of replacing the manager. I label these costs control costs and denote them by $c$. Thus, if revenues are $x$, shareholders' return from intervention is $x-c$. In the model, control costs, thus, act as a convenient summary of the different elements that determine shareholder power, such as the firm's ownership structure, the degree of legal protection of shareholders, or the inclusion of amendments in the firm's charter that impede the replacement of the manager or the board.

\subsection{Sequence of events}

There are two features of the sequence of events described in Figure 1 that deserve comment. First, as described above, the assumption that the manager's compensation is determined after the firm's outcome is realized is not arbitrary, but meant to reflect both the manager's ability to determine his own compensation and his inability, due to the very same reasons, to commit ex ante to any

\footnotetext{
${ }^{13}$ In modelling shareholder intervention as managerial replacement, I also follow Fluck (1998, 1999) and Myers (2000).

${ }^{14}$ See Bebchuk (2007) for a detailed account of these costs.
} 
compensation contract that does not ex post give him the maximum possible pay.

The second feature that deserves comment is the assumption that shareholders' intervention decision takes place after the manager announces the return that will be paid to shareholders. In a one-period model, this return is meant to capture the part of the cash flow generated by the firm that accrues to shareholders and, thus, can be equally understood as profits or the value of the firm's equity. The assumption that shareholders react to profit announcements and not to actual dividend payments is necessary in a one-period model. In such a model, there is no room for disciplining the manager after payoffs have been distributed (unless shareholders could somehow force the manager to return part of his pay), so the manager would extract all rents. With the assumption that shareholders react to the manager's profit announcement, the model is to be interpreted as a reduced-form version of a repeated-interaction model, such as the ones developed by Fluck (1998) and Myers (2000), in which the manager pays dividends each period and shareholders base their intervention decision on past dividend payments. ${ }^{15}$

\section{Control costs and incentives}

In this section, I analyze how control costs determine the manager's action choice and expected pay. To do so, I proceed by backward induction: first, I analyze shareholders' decision as to whether to accept the manager's offer or to intervene; then, I analyze the manager's optimal offer; and, finally, I study the manager's action choice.

\subsection{Optimal return announcement and managerial compensation}

Shareholders will accept any return offer at least as high as the profits, net of the costs of intervention, that they can obtain if they intervene, $x-c$. If shareholders accept an offer $d$, the manager's compensation is $m=x-d$. It follows that, for any $x$, the manager will make the lowest offer

\footnotetext{
${ }^{15}$ In a more literal interpretation of the model, the return obtained by shareholders can be understood as a liquidation dividend.
} 
acceptable to shareholders. Therefore, the manager's optimal announcement strategy is:

$$
d(x)= \begin{cases}0 & \text { if } x<c \\ x-c & \text { if } x \geq c\end{cases}
$$

Since owners will always accept $d(x)$, the manager's compensation is:

$$
m(x)= \begin{cases}0 & \text { if } x<0 \\ x & \text { if } 0<x<c \\ c & \text { if } x>c\end{cases}
$$

Therefore, the performance-pay profile implied by the model's pay setting process is concave, as illustrated in Figure 2: while for low levels of revenues $(x<c)$, the manager is the sole residual claimant, for higher levels of revenues $(x<c)$, the manager's compensation is flat. It is worth noting that this pattern is opposite to the one that would characterize an optimal contract between a risk neutral principal and a risk-neutral agent in the presence of two-sided limited liability (Innes, 1990). It also differs starkly from the convex performance-pay relation implied by stock options. It is worth remarking, however, that, in a dynamic setting, stock options are compatible with the performance-pay relation in Figure 2 if option grants are timed strategically.

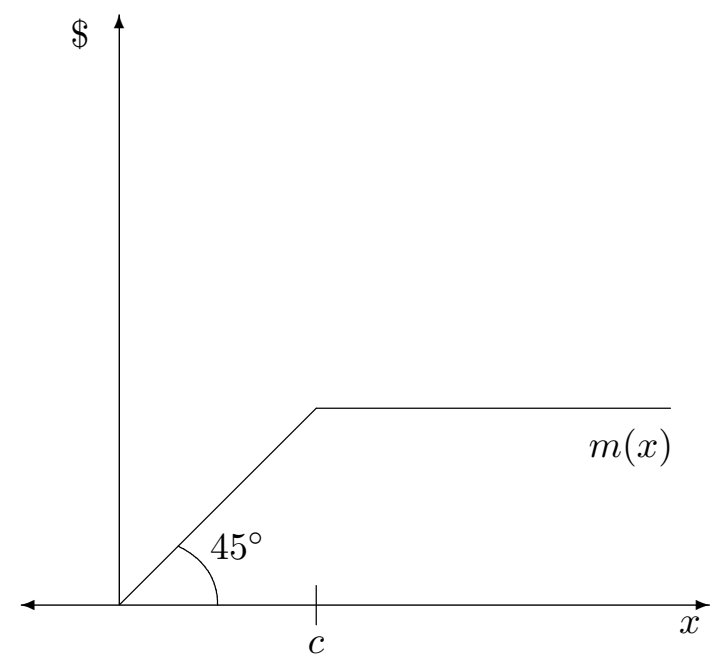

Figure 2: Compensation as a function of revenues.

It is important to note that the manager's optimal return policy guarantees that there is no shareholder intervention in equilibrium. The threat of owner intervention, nonetheless, determines 
both shareholder returns and managerial compensation in equilibrium.

\subsection{The manager's action choice}

If the manager chooses action $a$, his compensation, as a function of the stochastic component of revenues, $\epsilon$, is:

$$
m(\epsilon \mid a, c, \theta)= \begin{cases}0 & \text { if } \epsilon<-p a \\ p a+\epsilon & \text { if }-p a<\epsilon<-p a+c \\ c & \text { if } \epsilon>-p a+c\end{cases}
$$

Therefore, for a given level of $a$, there are three distinct regions in the support of $\epsilon$. In the first region $(\epsilon<-p a)$, revenues are negative, so the manager's compensation is zero. ${ }^{16}$ In the second region $(-p a<\epsilon<-p a+c)$, revenues are lower than control costs, so the manager keeps all revenues generated by the firm. Finally, in the third region $(\epsilon>-p a+c)$, the manager has to pay $x-c$ to shareholders, so his compensation is $c<x$. It follows that the manager's expected compensation for a given effort level $a$ is:

$$
E m(a, c, \theta) \equiv E(m(\epsilon \mid a, c, \theta))=\int_{-p a}^{-p a+c}(p a+\epsilon) \phi(\epsilon) d \epsilon+\int_{-p a+c}^{\infty} c \phi(\epsilon) d \epsilon
$$

Applying Leibniz's rule, we can see how the net change in expected compensation caused by an increase in $a$ is:

$$
\begin{aligned}
\frac{\partial E m}{\partial a} & =-p c \phi(-p a+c)+p(p a-p a) \phi(-p a)+\int_{-p a}^{-p a+c} p \phi(\epsilon) d \epsilon+p c \phi(-p a+c)= \\
& =\int_{-p a}^{-p a+c} p \phi(\epsilon) d \epsilon>0
\end{aligned}
$$

Therefore, the marginal return of effort for the manager is the expected marginal increase in pay in the region in which the manager is the sole residual claimant.

If we let $E U(a, c, \theta)$ denote the manager's expected utility as a function of $a$ (given $c$ and the parameter vector $\theta)$, then:

$$
E U(a, c, \theta) \equiv \operatorname{Em}(a, c, \theta)-\frac{\alpha a^{2}}{2}
$$

\footnotetext{
${ }^{16}$ Limited liability ensures that, in this case, both the manager and shareholders obtain a payoff of zero.
} 
The manager will choose the level of effort that maximizes $E U$, which is given by the first-order condition $^{17}$

$$
p \int_{-p a^{*}}^{-p a^{*}+c} \phi(\epsilon) d \epsilon-\alpha a^{*}=0
$$

\subsection{Control costs, optimal effort and pay}

How does the level of control costs affect the structure and level of pay and the manager's choices? Inspection of Figure 2 reveals that the effect of an increase in $c$ is twofold. On the one hand, it raises the maximum level of revenues for which the manager is the sole residual claimant. On the other hand, it increases the compensation that the manager obtains for any realization of profits that leads to a positive return for shareholders. It follows that for any $a$, expected pay goes up when $c$ increases. Further, the fact that an increase in $c$ widens the region in which the manager is the residual claimant suggests that increasing $c$ may give the manager greater incentives to select a high level of $a$. Inspection of the first-order condition (FOC) indeed shows that an increase in $c$ increases the manager's marginal return of effort. Therefore, $a^{*}$ will increase with $c$, as stated in the following proposition (all proofs are in the appendix):

Proposition 1 Let $a^{*}(c, \theta)$ be the manager's action choice given $c$ and $\theta$. Then: 1) $a^{*}(c, \theta)$ is increasing in c; 2) $E U\left(a^{*}(c, \theta), c, \theta\right)$ is increasing in $c$; and 3) $\operatorname{Em}\left(a^{*}(c, \theta), c, \theta\right)$ is increasing in $c$.

Part 1) runs counter usual expectations regarding the relationship between shareholders' ability to discipline the manager and performance. While it is usually assumed that higher costs of control will negatively affect performance, Proposition 1 shows that if the manager has the power to set his own compensation, greater costs of control increase his incentives to maximize profits. The intuition behind parts 2) and 3) is straightforward: an increase in $c$ increases the manager's expected compensation for any level of $a$; since expected pay is also increasing in $a$, it follows from part 1)

\footnotetext{
${ }^{17}$ Even though $E U$ may not be globally concave, it can be shown (see Appendix B) that the first-order condition uniquely identifies the manager's optimum.
} 
that expected pay must go up when $c$ increases (part 3). Further, since a higher $c$ raises expected utility for any level of $a$, the manager must be able to do better when $c$ increases (part 2).

The following proposition provides further predictions regarding the relationship between the manager's expected compensation and parameters that reflect the manager's productivity $(p)$ and the severity of the conflict of interest between the manager and shareholders $(\alpha)$ :

Proposition 2 Let $\operatorname{Em}^{*}(c, \theta) \equiv \operatorname{Em}\left(a^{*}(c, \theta), c, \theta\right)$. Then, Em* is increasing in $p$ and decreasing in $\alpha$.

Expected compensation increases with $p$, since a larger $p$ increases pay for any $a$, and induces the manager to exert more effort. When the opportunity cost of effort is greater ( $\alpha$ increases), on the other hand, it is optimal for the manager to lower effort provision, reducing expected pay.

\section{Control costs, efficiency and profits}

One of the key questions in the study of corporate governance is whether and how corporate governance influences firm performance. In this section, I analyze the effect of changes in control costs on different performance measures.

\subsection{Control costs and efficiency}

Proposition 1 shows that an increase in control costs increases effort and, thus, suggests that greater control costs may reduce the efficiency loss stemming from the agency relationship between shareholders and the manager. The following proposition shows that, for any level of control costs, there is underprovision of effort. Therefore, higher control costs - by leading to greater effort provision - indeed have the effect of increasing both expected revenues and expected total firm value (the sum of the manager's expected utility and expected profits). Let $E V(a, \theta)=$

$\int_{-p a}^{\infty}(p a+\epsilon) \phi(\epsilon) d \epsilon-\frac{\alpha a^{2}}{2}$ denote total expected firm value and $a_{e}(\theta)$ denote the value-maximizing level of $a: a_{e}(\theta)=\arg \max _{a} E V(a, \theta)$. Further, let $E x^{*}(c, \theta) \equiv E\left(x \mid a^{*}(c, \theta), \theta\right)$ be the expected 
revenue generated by the project, and $E V^{*}(c, \theta) \equiv E V\left(a^{*}(c, \theta), \theta\right)$ the total expected firm value if the manager selects $a^{*}(c, \theta)$. With this notation, I can state the following proposition:

Proposition 3 For any $c, \theta: 1) a^{*}(c, \theta) \leq a_{e}(\theta)$; and 2) $E x^{*}(c, \theta), E V^{*}(c, \theta)$ are increasing in $c$.

Proposition 3 shows that for any level of control costs, it is optimal to further increase $c$. To interpret this result, however, it is essential to bear in mind its second-best nature. Proposition 3 states that, if the board is captured by the manager, so the latter cannot be given an optimal ex ante compensation contract, then it is value-increasing to raise control costs. If low enough levels of control costs guaranteed that the board would serve shareholders' interests, however, then it would be globally optimal to reduce control costs to zero. Therefore, the practical implication of Proposition 3 is that, if there were a lower bound for $c$, then it may be optimal to increase control costs beyond that lower bound. Suppose, for example, that the need for diversification by investors implies that the ownership structure of large firms will necessarily be dispersed. Further, suppose that regulation alone cannot prevent the manager from capturing the director nomination process, so that, in the absence of active intervention by shareholders, the board will act in the interest of the manager. In such a context, there will be a lower bound for $c$ and Proposition 3 implies that it may not be optimal to bring control costs down to that lower bound. Therefore, Proposition 3 suggests caution when evaluating corporate governance reform proposals aimed at increasing shareholder power.

\subsection{Control costs and profits}

Although higher control costs, by increasing effort provision, translate into higher expected revenues, they also have the direct effect of reducing shareholders' payoff for any realization of revenues. Therefore, the net effect of an increase in control costs on profits cannot be signed a priori. To determine the sign of this net effect, consider expected profits if the manager takes action $a^{*}(c, \theta)$ :

$$
E d^{*}(c, \theta) \equiv \int_{-p a^{*}+c}^{\infty}\left(p a^{*}+\epsilon-c\right) \phi(\epsilon) d \epsilon
$$


Applying Leibniz's rule we obtain:

$$
\frac{\partial E d^{*}}{\partial c}=\left(p a_{c}^{*}-1\right) \int_{-p a^{*}+c}^{\infty} \phi(\epsilon) d \epsilon
$$

where $a_{c}^{*}=\frac{\partial a^{*}}{\partial c}$. It follows that the sign of the effect of an increase in control costs on profits depends on whether an increase in control costs leads to an even greater increase in expected revenues. The following proposition describes the relation between control costs and expected profits:

\section{Proposition 4}

1. If $\left(\frac{p^{2}}{\alpha}\right)>\left(\frac{1}{\phi(0)}\right)$, then there exists a $\tilde{c}(\theta)>0$, such that $E d^{*}(c, \theta)$ is increasing in $c$ for $c<\tilde{c}(\theta)$ and decreasing for $c>\tilde{c}(\theta)$.

2. If $\left(\frac{p^{2}}{\alpha}\right)<\left(\frac{1}{\phi(0)}\right)$, then $E d^{*}(c, \theta)$ is decreasing in $c$ for all $c$.

Therefore, the relationship between control costs and profits may not be monotonic. If $\left(\frac{p^{2}}{\alpha}\right)$ is high enough, an increase in control costs reduces profits when control costs are high, but it raises profits when control costs are low. The ratio $\left(\frac{p^{2}}{\alpha}\right)$ is a measure of the sensitivity of the manager's action choice $a^{*}$ to changes in control costs, on the one hand, and of the sensitivity of expected profits to changes in $a^{*}$, on the other. Thus, if $p$ is large, an increase in $c$ has a large impact on expected compensation and, thus, increases the sensitivity of the manager's effort to changes in $c$. Further, an increase in $p$ amplifies the impact on expected profits of an increase in $a^{*}$. If the conflict-of-interest parameter $\alpha$ is high, control costs increases will have a smaller effect on $a^{*}$, since a higher $\alpha$ implies a higher marginal cost of effort. The right-hand side of the inequalities in Proposition 4 is the value of the normal p.d.f. at zero and is a measure of the precision with which the manager's actions translate into revenues: the higher $\phi(0)$, the more the distribution of revenues concentrates around $p a$. It should be emphasized that the condition $\left(\frac{p^{2}}{\alpha}\right)>\left(\frac{1}{\phi(0)}\right)$ is not only plausible, but, as I show in Section 4, is actually necessary for financing to be possible under reasonable restrictions on the parameters. 


\section{Control costs and firm financing}

Higher control costs increase the total value generated by the firm, yet, eventually they also reduce shareholders' expected return. Therefore, for high enough levels of control costs, there will be a trade-off between increasing total firm value and securing investors a return that is sufficient to induce them to invest in the project. In this section, I analyze this trade-off and determine the levels of control costs that allow the entrepreneur to finance the project.

If investors correctly anticipate the manager's choice of action, the maximum they will be willing to pay for the firm's equity will be the expected return that they would obtain if the project is carried out: $\operatorname{Ed}^{*}(c, \theta)$. I will assume, as customary (see, e.g., Tirole, 2001), that the capital market is competitive and the interest rate is zero, so investors will pay exactly $P_{E}=E d^{*}(c, \theta)$ for the equity offered to them by the entrepreneur. Financing will be possible if and only if $P_{E} \geq I$, that is, if and only if the following financing constraint holds:

$$
\operatorname{Ed}^{*}(c, \theta) \geq I
$$

For the problem to be interesting, I make two assumptions about $I$. The first one is that the net present value of the project is negative if the manager exerts no effort:

Assumption AS.1 $\int_{0}^{\infty} \epsilon \phi(\epsilon) d \epsilon<I$.

Note that this assumption implies that if $p a \leq c$, then $E d^{*}<I$, so, that, for financing to be possible, it must be the case that $p a^{*}(c, \theta)>c$, i.e., expected revenues must exceed the costs of control.

The second assumption is that it would be worth it for the manager to undertake the project if he had the $I$ dollars necessary to carry it out. If the manager were the sole owner of the firm, he would choose action $a_{e}(\theta)$, which is defined above as the action that maximizes total expected firm value. Thus, I require:

Assumption AS.2 $E V\left(a_{e}(\theta), \theta\right)-I>0$. 
If AS.2 did not hold, financing would not be possible for any level of $c$. Under Assumptions AS.1 and AS.2, it is straightforward to show that:

Proposition 5 If financing is possible for some $c$, then it is possible if and only if $c \in[\underline{c}(\theta), \bar{c}(\theta)]$, where $\underline{c}(\theta)>0$.

This proposition follows immediately from Propositions 1 and 4 and from Assumption AS.1. First, AS.1 implies that financing is not possible when $c=0$, since if $c=0$, then $a^{*}(0, \theta)=0 .{ }^{18}$ Therefore, financing will be possible only if $c>0$ and if shareholder returns are increasing in $c$ at least for low values of $c$ (i.e., according to Proposition 4 , only if $\left.p^{2} / \alpha>1 / \phi(0)\right)$. The latter requirement is necessary, since, Assumption AS.1 implies that expected profits at $c=0$ are lower than $I$, so that, if they were decreasing in $c$, they would be lower than $I$ for any $c$. Second, Proposition 4 shows that, even if expected profits increase in $c$ for low values of $c$, they are decreasing in $c$ for $c$ large enough. In fact, if $E d^{*}(c, \theta)>I$ for some $c$, then there is a $\bar{c}(\theta) \geq 0$, such that $E d^{*}(\bar{c}(\theta), \theta)=I$ and $E d^{*}(\bar{c}(\theta), \theta)<I$ for $c>\bar{c}(\theta) .{ }^{19}$ Therefore, if financing is possible, then it is possible only for an interval of control costs bounded away from zero.

Proposition 5 has the implication that if managerial incentives are provided only by the threat of shareholder intervention, a positive level of control costs is not only compatible, but necessary for the firm to obtain financing. I discuss this implication in greater detail in Section 6 .

\section{Optimal control costs}

Control costs may be partly determined by factors beyond the entrepreneur's control, like the quality of the legal system or the listing requirements of the exchange where the firm's shares are issued. However, at the IPO stage, the entrepreneur has some leeway to determine the magnitude of control costs. This can be done by including provisions in the firm's charter that make it

\footnotetext{
${ }^{18}$ If $c=0$, then $E U(a, 0, \theta)=\int_{-p a}^{-p a}(p a+\epsilon) \phi(\epsilon) d \epsilon+\int_{-p a}^{\infty} 0 \phi(\epsilon) d \epsilon-\frac{\alpha a^{2}}{2}=-\frac{\alpha a^{2}}{2}$, so the optimal level of effort is $a^{*}(0, \theta)=0$.

${ }^{19}$ This follows from continuity of $E d^{*}$ and the fact that, for $c$ high enough, $E d^{*}<I$. To see this, let $c_{0} \geq p a_{e}(\theta)$. Since $a^{*}(c, \theta) \leq a_{e}(\theta)$ for any $c$, it follows that $p a^{*}\left(c_{0}, \theta\right) \leq p a_{e}(\theta) \leq c_{0}$. Therefore, Assumption AS.1 implies that $E d^{*}\left(c_{0}, \theta\right)<I$.
} 
difficult to oust a board, by selecting a manager-friendly board, or by means of the initial choice of ownership structure (with, for example, a more dispersed ownership structure leading to higher costs of control because of small individual stakes and severe free-rider problems). To the extent that the entrepreneur has the ability to determine the costs of control, we should expect that these costs will be set so as to maximize the entrepreneur's ex ante expected utility. Letting $E U^{*}(c, \theta)$ denote this ex ante expected utility, we obtain that if the entrepreneur obtains financing:

$$
\begin{aligned}
E U^{*}(c, \theta) & =\left(P_{E}-I\right)+E U\left(a^{*}(c, \theta), c, \theta\right)=E d^{*}(c, \theta)-I+E m\left(a^{*}(c, \theta), c, \theta\right)-\frac{\alpha a^{* 2}}{2}= \\
& =\int_{-p a^{*}}^{\infty}\left(p a^{*}+\epsilon\right) \phi(\epsilon) d \epsilon-\frac{\alpha a^{* 2}}{2}-I=E V\left(a^{*}(c, \theta), \theta\right)-I
\end{aligned}
$$

where the second equality comes from the competitive capital market assumption $P_{E}=E d^{*}$. The entrepreneur's ex ante expected utility is, thus, equal to the expected utility (net of investment costs) that he would obtain if he were the sole owner of the firm and took action $a^{*}$. Therefore, the entrepreneur will set the level of $c$ so as to maximize the value of the venture. Since i) this value $(E V(a, \theta))$ is increasing in $a$ for any $a$ below the efficient level $a_{e}(\theta)$; ii) the manager's choice, $a^{*}(c, \theta)$, is below the efficient level $a_{e}(\theta)$ for any $c$; and iii) $a^{*}(c, \theta)$ is increasing in $c$, it follows that the optimal level of control costs is the maximum compatible with financing:

Proposition 6 The unique optimal level of control costs $c^{*}(\theta)$ is defined by:

1. $E d^{*}\left(c^{*}(\theta), \theta\right)=I$, and

2. $c^{*}(\theta)>\tilde{c}(\theta)$,

for $\tilde{c}$ defined in Proposition 4. Since $E d^{*}(c, \theta)$ is increasing in $c$ for low values of $c$ when financing is possible, the second condition in the proposition ensures that the optimum is in the region of control costs where expected shareholder returns are decreasing in $c$ (since, otherwise, further increasing $c$ would increase value without precluding financing). 


\section{Discussion of the results}

In this section, I derive comparative statics results regarding the determinants of control costs and their relation with firm performance, and present some additional implications of the model.

\subsection{Determinants of control costs}

Proposition 6 characterizes the optimal level of control costs. To the extent that control costs are set optimally by entrepreneurs, we can derive how these control costs will vary when parameter values change:

Proposition 7 The optimal level of control costs is decreasing in $\alpha$ and $I$ and increasing in $p$.

To understand this result, one should recall that for any level of control costs, there is underprovision of managerial effort $\left(a^{*}(c, \theta) \leq a_{e}(\theta)\right)$. Therefore, since the entrepreneur captures ex ante the whole net present value of the project, he will always try to set $c$ as high as allowed by the financing constraint. Thus, any change that relaxes the financing constraint will increase the optimal cost of control, while any change that makes the financing constraint stricter will reduce the optimal cost of control. The effect of $I$ on control costs is, thus, immediate: a higher $I$ does not have any direct effect on effort provision and makes the financing constraint stricter. Therefore, increases in $I$ reduce $c^{*}$. It is important to notice that, other things equal, an increase in $I$ amounts to a reduction of the net present value of the project. Therefore, Proposition 7 implies that projects with a lower net present value should be associated with a lower $c^{*}$. Increases in $\alpha$ do not have any direct effect on the financing constraint, but reduce effort provision for any level of $c$ and, thus, make the financing constraint more demanding. Finally, changes in $p$ have both direct and indirect effects on the financing constraint, since they have an effect on expected profits for fixed $c$ and $a$ and also on effort provision for given $c$. The net effect of an increase in $p$ is always to relax the financing constraint, so a higher $p$ implies a higher optimal level of control costs. Proposition 7, in sum, predicts that control costs will be higher (i.e., shareholder power will be lower) in firms 
where the conflict of interest between shareholders and the manager is less severe, for projects with higher returns on assets, or where the impact of the manager's actions on revenues is larger.

\subsection{Optimal control costs and performance}

In Section 3, I studied the impact of changes in control costs on performance, other things equal. To the extent that control costs can be considered mainly exogenous for the individual entrepreneur, Propositions 3 and 4 can be interpreted as providing predictions regarding the relation between control costs and different measures of performance. If, however, control costs can be considered as being to a large extent determined by the entrepreneur, then, to obtain empirical predictions about the relation between control costs and performance, one has to analyze the equilibrium determination of control costs and performance and investigate how equilibrium values respond to changes in parameters. Here, I carry out this analysis and evaluate the hypothesis advanced by Demsetz (1983) that there should be no relationship between the quality of corporate governance and performance if corporate governance arrangements are optimally set, since, in such a case, corporate governance would have been chosen to maximize value. It is important to note that, even if we assume that control costs are set optimally, there can still exist an equilibrium relationship between control costs and performance if performance measures and control costs co-vary in a consistent way when parameter values change. For example, a higher marginal return of managerial effort could lead to both a higher optimal cost and higher equilibrium revenues. The following proposition shows that if performance is measured in terms of revenues or in terms of total value, there will exist a positive equilibrium correlation between control costs and performance:

Proposition 8 Let $E x^{* *}(\theta)=E x^{*}\left(c^{*}(\theta), \theta\right)$ and $E V^{* *}(\theta)=E V^{*}\left(c^{*}(\theta), \theta\right)$. Then, $E x^{* *}(\theta)$, $E V^{* *}(\theta)$ and $c^{*}(\theta)$ vary in the same direction in response to changes in any parameter value.

The intuition behind this result is as follows. A change in any parameter value affects ex ante expected revenues, $E x^{* *}(\theta)=p a^{*}\left(c^{*}(\theta), \theta\right)$, in three ways. First, it may directly affect expected revenues for fixed $a$ and $c$. Second, it influences the manager's choice of effort even if $c^{*}$ does 
not change. And, third, it affects the choice of effort indirectly through its effect on $c^{*}$. For all parameters, all three effects operate in the same direction, so a change in any parameter has an unambiguous effect on $E x^{* *}$. This implies, in particular, that the sign of the effect of the change in the parameter value on $c^{*}$ and $E x^{* *}$ is the same. For example, an increase in $p$, increases the return of the manager's effort, leads the manager to exert more effort for any value of $c$, and increases $c^{*}$, which also leads to greater effort. An analogous argument holds for $E V^{* *}$.

If we consider as our measure of performance the return obtained by shareholders on their investment, however, Demsetz's (1983) prediction that there should be no relation between control costs and performance is borne out trivially because of the assumption that capital markets are competitive. Given this assumption, $P_{E}=E d^{*}$ for any project that obtains financing; therefore, shareholders always obtain the rate of return of the alternative asset (which I assumed to be zero). It is more interesting to consider as our measure of performance shareholders' return on the firm's assets (which, in our context, is analogous to Tobin's $q$ ). Thus, let $Q^{*}(c, \theta)$ denote the return on the firm's assets when $a=a^{*}(c, \theta)$, and $Q^{* *}(\theta)=E d^{*}\left(c^{*}(\theta), \theta\right) / I$ denote the return on the firm's assets when $a=a^{*}(c, \theta)$ and $c$ is set optimally. Since $E d^{*}=I$ if $c$ is set optimally, then:

Proposition $9 Q^{* *}(\theta)=1$ for any $\theta$ for which financing is possible.

It is worth remarking that, if $c$ were not set optimally, then $Q^{*}$ could be higher than one and it would not be possible to sign a priori the relation between $Q^{*}$ and control costs. It is also important to note when interpreting Propositions 7, 8 and 9 that they rely both on the assumptions about the executive pay-setting process and on the assumption that investors correctly anticipate the effect of control costs and parameter values on the manager's behavior.

\subsection{Optimal anti-takeover protection at the IPO stage}

Proposition 5 states that financing requires a positive level of control costs and that it may be compatible with relatively large control costs. This prediction may help explain the finding that firms going public consistently include provisions in their charters, such as anti-takeover provisions 
(ATPs), that make replacing the management team more difficult for shareholders (Daines and Klausner, 2001; Field and Karpoff, 2002). These provisions have been regarded as puzzling (Daines and Klausner, 2001) under the assumption that they create agency costs that reduce firm value: if their negative effect on firm value were correctly predicted by investors, the agency costs induced by ATPs would be ultimately borne by the entrepreneur going public, who would, thus, want to eliminate ATPs from firms' charters. The model provides an explanation for this apparent puzzle, as it shows that, because of the incentive effect of control costs, their optimal level will be positive. It is interesting to note that, consistently with the prediction of Proposition 9, Field and Karpoff (2002) document no significant differences in long-run performance (measured as operating return on assets) between IPO firms with and without takeover defenses (although they do find better performance in the short-run for IPO firms with takeover defenses). These results are, however, in contrast with those obtained in studies, such as the one by Gompers, Ishii, and Metrick (2003), that consider seasoned firms.

\subsection{Optimal ownership structure and performance}

To the extent that ownership structure is relatively stable over time or that there is a positive and monotonic relation between ownership concentration at the IPO stage and long term ownership concentration, ${ }^{20}$ propositions 6 and 7 also have implications regarding firms' optimal ownership structure. Let us assume, along the lines of Burkart, Gromb, and Panunzi (1997), that only the largest shareholder bears the cost of intervention, and let $l$ be the ownership share of the largest shareholder. Suppose further that total control costs are $C$, which cannot be determined by the entrepreneur and are independent of ownership structure. To avoid intervention by the largest shareholder, the manager has to offer a return $d(x)$ such that $l d(x) \geq l x-C$. Therefore:

$$
d(x)=\max \left\{0, x-\frac{C}{l}\right\}
$$

\footnotetext{
${ }^{20}$ Kaplan, Sensoy, and Strömberg (2006) report large changes in ownership structure in the first three years after the IPO for a sample of venture capital-funded firms. Ownership structure at the IPO stage, however, could still be monotonically related to long-term ownership structure.
} 
Letting $c=\frac{C}{l}$, one can carry out the analysis like in previous sections and obtain the optimal ownership share of the largest shareholder as $l^{*}(\theta)=\frac{C}{c^{*}(\theta)}$, where $c^{*}(\theta)$ is the optimal level of control costs. As in Burkart, Gromb, and Panunzi (1997), if $c^{*}(\theta)>C$ (which will happen if $C$ is small), too much shareholder control may be counterproductive, even if we abstract from the potential liquidity or diversification costs to be borne by the largest shareholder. Further, concentration will be larger the larger the exogenous level of control costs $(C)$. Finally, Proposition 7 provides predictions about the determinants of ownership concentration: ownership concentration will be increasing in $\alpha$ and $I$ and decreasing in $p$. It is worth noting that Proposition 9 implies that if $l$ is set optimally, firms' returns on assets should be independent of ownership concentration, as originally proposed by Demsetz (1983).

\subsection{Firm size and control costs}

In previous sections, I have investigated the effects of changes in $I$, other things equal, on the manager's action choice, expected compensation and the optimal level of control costs. As remarked in Subsection 6.1, changes in $I$ should be interpreted as changes in the net present value of the project, and not as changes in project size, since one would expect changes in size to affect not only the required initial investment, but also the expected value of the project. To investigate the effect of size, I assume next that revenues are given by:

$$
x=s+p a+\epsilon,
$$

where $s$, the fixed component of revenues, measures the size of the investment project. I assume that $I=\psi(s)$ with $\psi^{\prime} \geq 1$, implying that it is not possible to increase the net present value of the project simply by increasing its size. To simplify notation, let $\bar{x}=s+p a$ and $\bar{x}^{*}=s+p a^{*}$. If revenues are determined according to equation (15), the manager's compensation if the project is financed is:

$$
m(\epsilon \mid a, c, s, \theta)= \begin{cases}0 & \text { if } \epsilon<-\bar{x} \\ \bar{x}+\epsilon & \text { if }-\bar{x}<\epsilon<-\bar{x}+c \\ c & \text { if } \epsilon>-\bar{x}+c\end{cases}
$$


An analysis analogous to the one in previous sections leads to the following predictions about the effect of size on managerial effort and optimal control costs:

\section{Proposition 10}

1. For any project that obtains financing, $a^{*}(c, s, \theta)$ is decreasing in $s$ for any $c, \theta$.

2. $\operatorname{Em}^{*}(c, s, \theta) \equiv \operatorname{Em}\left(a^{*}(c, s, \theta), c, s, \theta\right)$ is increasing in $s$ for any $c, \theta$.

3. The optimal level of control costs is decreasing in s for any $\theta$.

The result that effort is decreasing in size follows from the fact that an increase in size shifts to the left the region in the support of $\epsilon$ in which the manager is the residual claimant (see Figure 3). Therefore, as long as expected revenues are greater than control costs $\left(s+p a^{*}>c\right)$, the probability that the manager is the residual claimant (the shaded area in Figure 3) decreases as size increases. It follows that the manager's marginal return of effort decreases, which brings about the reduction in $a^{*}$. An increase in size has the direct effect of increasing expected compensation for any $a$. This direct effect is larger than the negative indirect effect on expected compensation due to the fall in $a^{*}$. Therefore, expected compensation increases in $s$, in accordance with the well known positive empirical correlation between firm size and pay. Part 3 follows from the fact that the combined negative effects on net present value of a higher $I$ and of a lower effort level (from Part 1) more than compensate the positive effect of size on net present value. Therefore, an increase in $s$ makes the financing constraint more demanding and lowers the optimal $c$.

It is worth remarking that, to derive Proposition 10, I have identified size with the fixed component of revenues and assumed that the initial investment is increasing in size. It is, however, conceivable that increases in size could be also accompanied by increases in $p$. In such a case, the effect of a change in size on $a^{*}$ and the optimal level of control costs would depend on the relative strength of the effect of the change in $s$ analyzed in Proposition 10 and of the effect of the corresponding change in the productivity parameter $p$. 


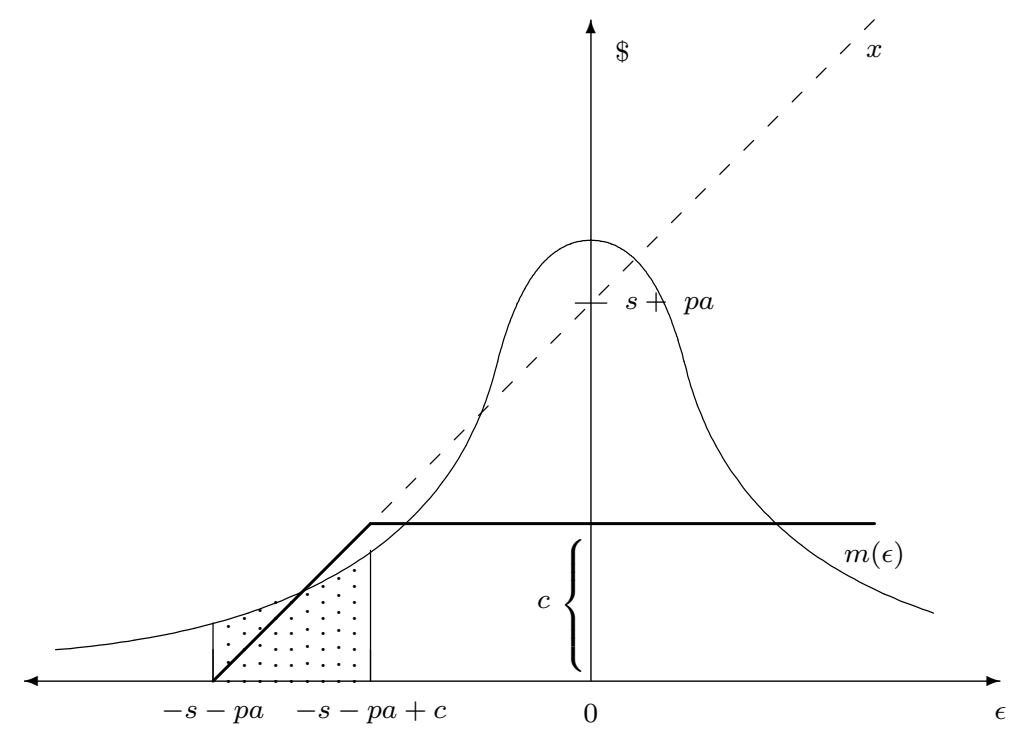

Figure 3: The impact of size $(s)$ on optimal effort.

\section{Conclusion}

This paper develops a model of the firm in which the manager enjoys real control over all decisions, including setting his own compensation, unless shareholders decide to exercise their control rights. The model allows us to study the consequences of managerial discretion over pay for compensation and incentives, and the effect that shareholder power has on those variables. The model shows, expectedly, that increasing shareholders' control costs (that is, reducing shareholder power) increases the level of managerial compensation. It also shows, less expectedly, that increases in control costs improve managerial incentives and lead to a higher total surplus. The positive effect of an increase in control costs on incentives may, in fact, be strong enough to lead to higher profits.

As a result of the incentive effects of control costs, the model predicts that a positive level of control costs may be not only compatible, but, in fact, necessary for firms to obtain financing. Thus, the model provides an explanation for the finding that firms' governance arrangements do not attempt to minimize control costs even at the going-public stage. The model also allows us to derive the optimal level of control costs for a firm going public, and shows that this optimal 
level is increasing in the return of the manager's effort and in the efficiency of the investment, and decreasing in the size of the project and the severity of the conflict of interest between the manager and shareholders.

Finally, the model yields predictions about the equilibrium relationship between optimal control costs and performance. When performance is measured in terms of expected cash flows or total surplus, the equilibrium relationship between firm performance and control costs is positive. However, when the measure of performance is shareholders' return on assets, there is no relationship between equilibrium performance and control costs.

This paper is, to my knowledge, the first attempt to provide a formal model of executive compensation in which the manager has discretion to set his own compensation. To highlight the main forces at work, I have left aside elements that are likely to play an important role in shaping managerial incentives and firms' financing choices in practice. These limitations of the model point at several interesting avenues for future research. First, I have investigated the role of shareholders' costs of control as determinants of the manager's compensation. However, other governance dimensions, such as the manager's ownership share or the degree to which the board is captured by the manager surely have an effect on the determination of the manager's compensation and, thus, on incentives as well. Analyzing how these different dimensions interact appears as an interesting extension of the model. Similarly, I have assumed that the entrepreneur issues equity to finance the project. Thus, I have left aside capital structure decisions and their effect on executive pay and incentives. I have also made the simplifying assumption that it is not possible to enforce any contingent contract. Although the analysis of partially incomplete contracts has proven elusive, this assumption could be relaxed so as to consider the constraints that managerial power imposes on the design of executive compensation contracts. Finally, I have ignored informational asymmetries, which are likely to play an important role in determining shareholders' intervention. Thus, while I have assumed that shareholders know the firm's state when deciding whether to intervene, most 
often, managers have superior information about the firm's prospects and can control the amount of information that is communicated to shareholders. The analysis of these informational asymmetries is left for future work. 


\section{References}

Adams, R. and D. Ferreira (2007). A theory of friendly boards. Journal of Finance 62(1), 217250.

Almazan, A. and J. Suarez (2003). Entrenchment and severance pay in optimal governance structures. Journal of Finance 58(2), 519-547.

Baker, G., R. Gibbons, and K. Murphy (1994). Subjective performance measures in optimal incentive contracts. Quarterly Journal of Economics 109(4), 1125-1156.

Barris, L. J. (1992). The overcompensation problem: A collective approach to controlling executive pay. Indiana Law Journal 68, 59-100.

Bebchuk, L. and J. Fried (2004). Pay without Performance: The Unfulfilled Promise of Executive Compensation. Harvard University Press.

Bebchuk, L. A. (2007). The myth of the shareholder franchise. Virginia Law Review, forthcoming.

Bernheim, B. D. and M. D. Whinston (1998). Incomplete contracts and strategic ambiguity. American Economic Review 88(4), 902-932.

Bertrand, M. and S. Mullainathan (2001). Are CEOs rewarded for luck? The ones without principals are. Quarterly Journal of Economics 116(3), 901-932.

Burkart, M., D. Gromb, and F. Panunzi (1997). Large shareholders, monitoring and the value of the firm. Quarterly Journal of Economics 112(3), 693-728.

Creswell, J. (2006). With links to Home Depot board, chief saw pay soar as stock fell. The New York Times, May 24.

Daines, R. and M. Klausner (2001). Do IPO charters maximize firm value? Antitakeover protection in IPOs. The Journal of Law, Economics, and Organization 17(1), 83-120.

DeAngelo, H. and E. M. Rice (1983). Antitakeover charter amendments and stockholder wealth. Journal of Financial Economics 11(1-4), 329-360. 
Demsetz, H. (1983). The structure of ownership and the theory of the firm. Journal of Law and Economics 26(2), 375-390.

Field, L. C. and J. Karpoff (2002). Takeover defenses of IPO firms. Journal of Finance, Vol. $57(5), 1857-1889$.

Fluck, Z. (1998). Optimal financial contracting: Debt versus outside equity. Review of Financial Studies 11(2), 383-418.

Fluck, Z. (1999). The dynamics of the management-shareholder conflict. Review of Financial Studies 12(2), 379-404.

Gabaix, X. and A. Landier (2006). Why has CEO pay increased so much? MIT, Department of Economics.

Gompers, P., J. Ishii, and A. Metrick (2003). Corporate governance and equity prices. Quarterly Journal of Economics 118(1), 107-155.

Hart, O. (1995). Corporate governance: Some theory and implications. Economic Journal 105(430), 678-689.

Hermalin, B. (2005). Trends in corporate governance. Journal of Finance 60(5), 2351-2384.

Hermalin, B. E. and M. S. Weisbach (1998). Endogenously chosen boards of directors and their monitoring of the CEO. American Economic Review 88(1), 96-118.

Hermalin, B. E. and M. S. Weisbach (2006). A framework for assessing corporate governance reform. SSRN eLibrary (http://ssrn.com/paper=881581).

Heron, R. A. and E. Lie (2007). Does backdating explain the stock price pattern around executive stock option grants? Journal of Financial Economics 83(2), 271-295.

Innes, R. D. (1990). Limited liability and incentive contracting with ex-ante action choices. Journal of Economic Theory 52(1), 45-67. 
Jensen, M. C., K. J. Murphy, and E. G. Wruck (2004). Remuneration: Where we've been, how we got to here, what are the problems, and how to fix them. Harvard NOM Working Paper No. 04-28.

Kaplan, S., B. Sensoy, and P. Strömberg (2006). What are firms? Evolution from early business plan to public companies. University of Chicago GSB, Working Paper.

Morgan, A., A. Poulsen, and J. Wolf (2006). The evolution of shareholder voting for executive compensation schemes. Journal of Corporate Finance 12(4), 715-737.

Morgenson, G. (2006). Big bonuses still flow, even if bosses miss goals. The New York Times, June 1.

Murphy, K. J. (1999). Executive compensation. In O. Ashenfelter and D. Card (Eds.), Handbook of Labor Economics, Volume IV, pp. 2485-2563. North Holland.

Murphy, K. J. and J. Zabojnik (2004). CEO pay and appointments: A market-based explanation for recent trends. American Economic Review Papers and Proceedings 94(2), 192-96.

Myers, S. C. (2000). Outside equity. Journal of Finance 55(3), 1005-1037.

Pagano, M. and A. Roell (1998). The choice of stock ownership structure: Agency costs, monitoring and the decision to go public. Quarterly Journal of Economics 113(1), 187-225.

Schwab, S. J. and R. Thomas (2006). An empirical analysis of CEO employment contracts: What do top executives bargain for? Washington $\&$ Lee Law Review 63(1), 231-270.

Singh, R. (2006). Board independence and the design of executive compensation. Harvard Business School, Working Paper.

Stein, J. C. (1988). Takeover threats and managerial myopia. Journal of Political Economy 96(1), $61-80$.

Stulz, R. M. (1988). Managerial control of voting rights: Financing policies and the market for corporate control. Journal of Financial Economics 20(1-2), 25-54. 
Tirole, J. (2001). Corporate governance. Econometrica 69(1), 1-35.

Yermack, D. (1997). Good timing: CEO stock option awards and company news announcements. Journal of Finance 52(2), 449-476.

Zingales, L. (1998). Corporate governance. In P. Newman (Ed.), The New Palgrave Dictionary of Economics and the Law. Palgrave Macmillan. 


\section{A Proofs}

Proof of Proposition 1. The unique optimal level of effort, $a^{*}(c, \theta)$, is identified by the firstorder condition: ${ }^{21}$

$$
p \int_{-p a^{*}}^{-p a^{*}+c} \phi(\epsilon) d \epsilon-\alpha a^{*}=0
$$

Thus, applying the Implicit Function Theorem, we obtain:

$$
a_{c} \equiv \frac{\partial a^{*}}{\partial c}(c, \theta)=\frac{p \phi\left(-p a^{*}+c\right)}{p^{2}\left[\phi\left(-p a^{*}+c\right)-\phi\left(-p a^{*}\right)\right]+\alpha}>0,
$$

since at $a^{*}, \frac{\partial^{2} E U}{\partial a^{2}}=-p^{2}\left[\phi\left(-p a^{*}+c\right)-\phi\left(-p a^{*}\right)\right]-\alpha<0$.

The fact that $E U$ is monotonically increasing in $c$ follows from the envelope theorem:

$$
\frac{\partial E U}{\partial c}\left(a^{*}, c, \theta\right)=c \phi\left(-p a^{*}+c\right)-c \phi\left(-p a^{*}+c\right)+\int_{-p a^{*}+c}^{\infty} \phi(\epsilon) d \epsilon>0
$$

Since $\frac{\partial a^{*}}{\partial c}>0$ implies that $\eta\left(a^{*}\right)$ increases with $c, \frac{\partial E U^{*}}{\partial c}\left(a^{*}(c, \theta), c, \theta\right)<\frac{\partial E m}{\partial c}\left(a^{*}(c, \theta), c, p\right)$. Thus, $\frac{\partial E m}{\partial c}\left(a^{*}(c, \theta), c, p\right)>0$.

Proof of Proposition 2. Implicit differentiation of the first-order condition yields:

$$
a_{\alpha} \equiv \frac{\partial a^{*}}{\partial \alpha}=\frac{-a^{*}}{p^{2}\left[\phi\left(-p a^{*}+c\right)-\phi\left(-p a^{*}\right)\right]+\alpha}<0
$$

Similarly,

$$
a_{p} \equiv \frac{\partial a^{*}}{\partial p}=\frac{\int_{-p a^{*}+c}^{-p a^{*}} \phi(\epsilon) d \epsilon-p a^{*}\left(\phi\left(-p a^{*}+c\right)-\phi\left(-p a^{*}\right)\right)}{p^{2}\left[\phi\left(-p a^{*}+c\right)-\phi\left(-p a^{*}\right)\right]+\alpha}
$$

Now, from

$$
\operatorname{Em}^{*}(c, \theta) \equiv \operatorname{Em}\left(a^{*}(c, \theta), c, \theta\right)=\int_{-p a^{*}}^{-p a^{*}+c}\left(p a^{*}+\epsilon\right) \phi(\epsilon) d \epsilon+\int_{-p a^{*}+c}^{\infty} c \phi(\epsilon) d \epsilon,
$$

\footnotetext{
${ }^{21}$ It can be shown (see Appendix B) that: 1) there is a unique $a^{*}(c, \theta)$ that satisfies the first-order condition; 2) $\frac{\partial^{2} E U}{\partial a^{2}}\left(a^{*}, c, \theta\right)<0$; and 3) $a^{*}(c, \theta)$ identifies the unique local and global optimal level of effort, even when $E U$ is not globally concave.
} 
it follows, applying Leibniz's rule, that

$$
\frac{\partial E m^{*}}{\partial \alpha}=\int_{-p a^{*}}^{-p a^{*}+c} p a_{\alpha} \phi(\epsilon) d \epsilon<0
$$

Similarly,

$$
\begin{aligned}
\frac{\partial E m^{*}}{\partial p} & =\left(a^{*}+p a_{p}\right) \int_{-p a^{*}}^{-p a^{*}+c} \phi(\epsilon) d \epsilon= \\
& =\left(\frac{\left.p \int_{-p a^{*}+c}^{-p a^{*}} \phi\right) d \epsilon+\alpha a^{*}}{p^{2}\left[\phi\left(-p a^{*}+c\right)-\phi\left(-p a^{*}\right)\right]+\alpha}\right)\left(\int_{-p a^{*}}^{-p a^{*}+c} \phi(\epsilon) d \epsilon\right)>0
\end{aligned}
$$

where the second equality follows from (20).

Proof of Proposition 3. Let

$$
E V(a, \theta)=\int_{-p a}^{\infty}(p a+\epsilon) \phi(\epsilon) d \epsilon-\frac{\alpha a^{2}}{2}
$$

If the manager were the sole owner of the firm, he would maximize $E V(a, \theta)$. As it was the case for Proposition 1, it can be shown (see Appendix B) that the properties of $\phi$ ensure that the first-order condition $\frac{\partial E V}{\partial a}=0$ is both necessary and sufficient for optimality, and that if we let $a_{e}(\theta)$ denote the maximizer of $E V$, then: 1) $a_{e}(\theta)$ is given by $\left.\frac{\partial E V}{\partial a}\left(a_{e}(\theta), \theta\right)=0 ; 2\right) a_{e}(\theta)$ is the unique local and global maximizer; and 3) $\frac{\partial E V}{\partial a}(a, \theta)>0$ for any $a<a_{e}(\theta)$ and $\frac{\partial E V}{\partial a}(a, \theta)<0$ for any $a>a_{e}(\theta)$. Thus, for $a^{*}$ defined by (FOC):

$$
\frac{\partial E V}{\partial a}\left(a^{*}, \theta\right)=p \int_{-p a^{*}}^{\infty} \phi(\epsilon) d \epsilon-\alpha a^{*}>p \int_{-p a^{*}}^{-p a^{*}+c} \phi(\epsilon) d \epsilon-\alpha a^{*}=0
$$

so $a^{*}(c, \theta)<a_{e}(\theta)$, for any $(c, \theta)$.

That $E x^{*}(c, \theta) \equiv E\left(x \mid a^{*}(c, \theta), c, \theta\right)$ is increasing in $c$ follows immediately from $a_{c}>0$. The facts that $a^{*}(c, \theta)<a_{e}(\theta)$ and $\frac{\partial E V}{\partial a}(a, \theta)>0$ for any $a<a_{e}(\theta)$, together with $a_{c}>0$, imply that $E V^{*}(c, \theta)=E V\left(a^{*}(c, \theta), \theta\right)$ is increasing in $c$.

Proof of Proposition 4. In the text, it was shown that

$$
\frac{\partial E d^{*}}{\partial c}=\left(p a_{c}-1\right) \int_{-p a^{*}+c}^{\infty} \phi(\epsilon) d \epsilon
$$


Therefore, $E d^{*}$ is increasing at $c$ if and only if $p a_{c}>1$. From (17), it follows that

$$
p a_{c}=\frac{p^{2} \phi\left(-p a^{*}+c\right)}{p^{2} \phi\left(-p a^{*}+c\right)-p^{2} \phi\left(-p a^{*}\right)+\alpha}
$$

Therefore $p a_{c}>1$ if and only if $\alpha<p^{2} \phi\left(-p a^{*}\right)$. Now, from $a_{c}>0$ and $\phi^{\prime}(a)>0$ for $a<0$, it follows that if $c_{1}>c_{0}$, then $p^{2} \phi\left(-p a^{*}\left(c_{1}, \theta\right)\right)<p^{2} \phi\left(-p a^{*}\left(c_{0}, \theta\right)\right)$. Therefore, if $p a_{c}\left(c_{0}, \theta\right)<1$, then $p a_{c}\left(c_{1}, \theta\right)<1$. It follows that a necessary and sufficient condition for $p a_{c}>1$ for some $c$ is $p a_{c}(0, \theta)>1$, that is:

$$
p^{2} \phi\left(-p a^{*}(0, \theta)\right)>\alpha
$$

Since $a^{*}(0, \theta)=0$, the last expression can be rewritten:

$$
\left(\frac{p^{2}}{\alpha}\right)>\left(\frac{1}{\phi(0)}\right)
$$

Further, if $p a_{c}(0, \theta)>1$, then $p a_{c}(c, \theta) \geq 1$ for any $c \in[0, \tilde{c}]$, where $\tilde{c}$ is defined implicitly by

$$
\alpha=p^{2} \phi\left(-p a^{*}(\tilde{c}, \theta)\right)
$$

Proof of Proposition 7. The optimal level of control costs, $c^{*}$, is such that $c^{*}>\tilde{c}$ (for $\tilde{c}$ defined in $(30))$ and:

$$
\int_{-p a^{*}\left(c^{*}, \theta\right)+c^{*}}^{\infty}\left(p a^{*}\left(c^{*}, \theta\right)+\epsilon-c^{*}\right) \phi(\epsilon) d \epsilon=I
$$

Implicit differentiation of (31) yields:

$$
c_{I} \equiv \frac{\partial c^{*}}{\partial I}=\frac{-1}{\left(1-p a_{c}\right)\left(\int_{-p a^{*}\left(c^{*}, \theta\right)+c^{*}}^{\infty} \phi(\epsilon) d \epsilon\right)}, \quad c_{\alpha} \equiv \frac{\partial c^{*}}{\partial \alpha}=\frac{p a_{\alpha}}{1-p a_{c}}, \quad c_{p} \equiv \frac{\partial c^{*}}{\partial p}=\frac{a^{*}+p a_{p}}{1-p a_{c}}
$$

By definition of $\tilde{c}$, it follows from $c^{*}>\tilde{c}$ that $1-p a_{c}>0$. Therefore, $c_{I}<0$. Now, from (19) we know that $a_{\alpha}<0$, so $c_{\alpha}<0$. Further $c_{p}>0$ since

$$
\left(a^{*}+p a_{p}\right)=\frac{p \int_{-p a^{*}+c}^{-p a^{*}} \phi(\epsilon) d \epsilon+\alpha a}{p^{2}\left[\phi\left(-p a^{*}+c\right)-\phi\left(-p a^{*}\right)\right]+\alpha}>0
$$


Proof of Proposition 8. Let $\operatorname{Ex}^{* *}(\theta)=\operatorname{Ex}^{*}\left(c^{*}(\theta), \theta\right)=p a^{*}\left(c^{*}(\theta), \theta\right)$. Then:

$$
\begin{aligned}
& \frac{\partial E x^{* *}}{\partial I}=p a_{c} c_{I}<0 \\
& \frac{\partial E x^{* *}}{\partial \alpha}=p a_{c} c_{\alpha}+p a_{\alpha}<0 \\
& \frac{\partial E x^{* *}}{\partial p}=a^{*}+p a_{c} c_{p}+p a_{p}=p a_{c} c_{p}+\left(a^{*}+p a_{p}\right)>0
\end{aligned}
$$

where the signs follow from Propositions 1 and 7, and from the proof of Proposition 2. Therefore, for any parameter $z, \frac{\partial E x^{* *}}{\partial z}$ and $c_{z}$ have the same sign (since it was shown in Proposition 7 that $c_{I}<0, c_{\alpha}<0$, and $\left.c_{p}>0\right)$. Analogous calculations show that $\frac{\partial E V^{* *}}{\partial z}$ and $c_{z}$ have the same sign, so $E V^{* *}$ and $c^{*}$ move in the same direction when any parameter changes.

Proof of Proposition 10. Now, the first-order condition of the manager's problem becomes:

$$
p \int_{-s-p a^{*}(c, s, \theta)}^{-s-p a^{*}(c, s, \theta)+c} \phi(\epsilon) d \epsilon-\alpha a^{*}(c, s, \theta)=0
$$

Defining $\bar{x}^{*} \equiv s+p a^{*}$, implicit differentiation yields:

$$
a_{s} \equiv \frac{\partial a^{*}}{\partial s}=-\frac{p\left[\phi\left(-\bar{x}^{*}+c\right)-\phi\left(-\bar{x}^{*}\right)\right]}{p^{2}\left[\phi\left(-\bar{x}^{*}+c\right)-\phi\left(-\bar{x}^{*}\right)\right]+\alpha}
$$

where the denominator is equal to $-\frac{\partial^{2} E U}{\partial a^{2}}\left(a^{*}, c, s, \theta\right)>0$. Since $\phi^{\prime}(\epsilon)>0$ for $\epsilon<0$ and $\phi^{\prime}(\epsilon)<0$ for $\epsilon>0$, and $\phi$ is symmetric about zero, it follows that $\phi\left(-\bar{x}^{*}+c\right)-\phi\left(-\bar{x}^{*}\right)<0$ if and only if $-\bar{x}^{*}+c>\bar{x}^{*}>0$, or $c>2 \bar{x}^{*}$. Therefore, recalling that $\bar{x}^{*}=s+p a^{*}$ :

$$
a_{s}<0 \Longleftrightarrow \phi\left(-\bar{x}^{*}+c\right)-\phi\left(-\bar{x}^{*}\right)>0 \Longleftrightarrow a^{*}>\frac{c-2 s}{2 p}
$$

Now, AS.1 implies that, for financing to be possible, $s+p a^{*}(c, s, \theta)>c$, or $a^{*}(c, s, \theta)>\frac{c-s}{p}$. Since $\frac{c-s}{p}>\frac{c-2 s}{2 p}$, it follows that if financing is possible, $a_{s}<0$. Further:

$$
\begin{aligned}
\frac{\partial E m^{*}}{\partial s} & =\left(1+p a_{s}\right) \int_{-\bar{x}^{*}}^{-\bar{x}^{*}+c} \phi(\epsilon) d \epsilon= \\
& =\left(\frac{\alpha}{p^{2}\left[\phi\left(-\bar{x}^{*}+c\right)-\phi\left(-\bar{x}^{*}\right)\right]+\alpha}\right)\left(\int_{-\bar{x}^{*}}^{-\bar{x}^{*}+c} \phi(\epsilon) d \epsilon\right)>0
\end{aligned}
$$


The optimal level of control $\operatorname{costs}, c^{*}(\theta)$, is such that $c^{*}(\theta)>\tilde{c}(\theta)$ and:

$$
\int_{-\bar{x}^{*}+c^{*}}^{\infty}\left(\bar{x}^{*}+\epsilon-c^{*}\right) \phi(\epsilon) d \epsilon=\psi(s)
$$

Implicit differentiation of (41) yields:

$$
\frac{\partial c^{*}}{\partial s}=\frac{\left(1+p a_{s}\right)\left(\int_{-\bar{x}^{*}+c^{*}}^{\infty} \phi(\epsilon) d \epsilon\right)-\psi^{\prime}(s)}{\left(1-p a_{c}\right)\left(\int_{-\bar{x}^{*}+c^{*}}^{\infty} \phi(\epsilon) d \epsilon\right)}<0,
$$

where the negative sign follows from the assumption that $\psi^{\prime} \leq 1$ and the fact that

$$
1+p a_{s}=\frac{\alpha}{p^{2}\left[\phi\left(-\bar{x}^{*}+c\right)-\phi\left(-\bar{x}^{*}\right)\right]+\alpha}<1
$$

The last inequality follows from the fact that for financing to be possible $\bar{x}^{*}>c$, which implies that $\phi\left(-\bar{x}^{*}+c\right)-\phi\left(-\bar{x}^{*}\right)>0$, since $\phi^{\prime}(\epsilon)>0$ for any $\epsilon<0$. 


\section{B Sufficiency of the First-Order Condition of the Manager's Prob- lem}

\section{Lemma B.1}

1. $E U(0, c, \theta)>0$ and $\frac{\partial E U}{\partial a}(0, c, \theta)>0$, for any $c>0$.

2. If $\frac{\partial E U}{\partial a}\left(a_{0}, c, \theta\right)=\frac{\partial E U}{\partial a}\left(a_{1}, c, \theta\right)=0$, then $a_{0}=a_{1}=a^{*}$, and $a^{*}$ is a global maximizer of $E U$.

Proof. The first part is proven immediately, since

$$
E U(0, c, \theta)=\int_{0}^{c} \epsilon \phi(\epsilon) d \epsilon+c \int_{c}^{\infty} \phi(\epsilon) d \epsilon>0
$$

and

$$
\frac{\partial E U}{\partial a}(0, c, \theta)=p \int_{0}^{c} \phi(\epsilon) d \epsilon>0, \text { for any } c>0
$$

Now, note that

$$
\frac{\partial^{2} E U}{\partial a^{2}}=-p^{2}[\phi(-p a+c)-\phi(-p a)]-\alpha
$$

Therefore, $\frac{\partial^{2} E U}{\partial a^{2}}>0$ only if $\phi(-p a+c)-\phi(-p a)<0$.

Since $\phi$ is the p.d.f. of a normal distribution: $\phi^{\prime}(t)>0$ if $t<0$, and $\phi^{\prime}(t)<0$ if $t>0$. Thus, if $p a>c$, then $\phi(-p a+c)-\phi(-p a)>0$. Further, symmetry of $\phi$ implies that for $q, b>0$, $\phi(-q)>\phi(b)$ if and only if $q<b$. Therefore, if $p a<c$, then $\phi(-p a+c)-\phi(-p a)>0$ whenever $p a>-p a+c$, that is, whenever $a>\frac{c}{2 p}$ (see Figure 4). Thus $\frac{\partial^{2} E U}{\partial a^{2}}<0$ for any $a>\frac{c}{2 p}$. Further, if $a<\frac{c}{2 p}$, then

$$
\frac{\partial^{3} E U}{\partial a^{3}}=p^{2}\left[p \phi^{\prime}(-p a+c)-p \phi^{\prime}(-p a)\right]<0,
$$

since if $a<\frac{c}{2 p}$, then $\phi^{\prime}(-p a+c)<0<\phi^{\prime}(-p a)$. Therefore, if $\frac{\partial^{2} E U}{\partial a^{2}}<0$ for some $a_{0}<\frac{c}{2 p}$, then $\frac{\partial^{2} E U}{\partial a^{2}}<0$ for any $a>a_{0}$. Further, if $\frac{\partial^{2} E U}{\partial a^{2}}<0$ at $a=0$, then $\frac{\partial^{2} E U}{\partial a^{2}}<0$ everywhere. Therefore, $\frac{\partial^{2} E U}{\partial a^{2}}>0$ for some $a$ if and only if $\frac{\partial^{2} E U}{\partial a^{2}}>0$ at $a=0$, which holds if and only if:

$$
p^{2}[\phi(0)-\phi(c)]>\alpha
$$




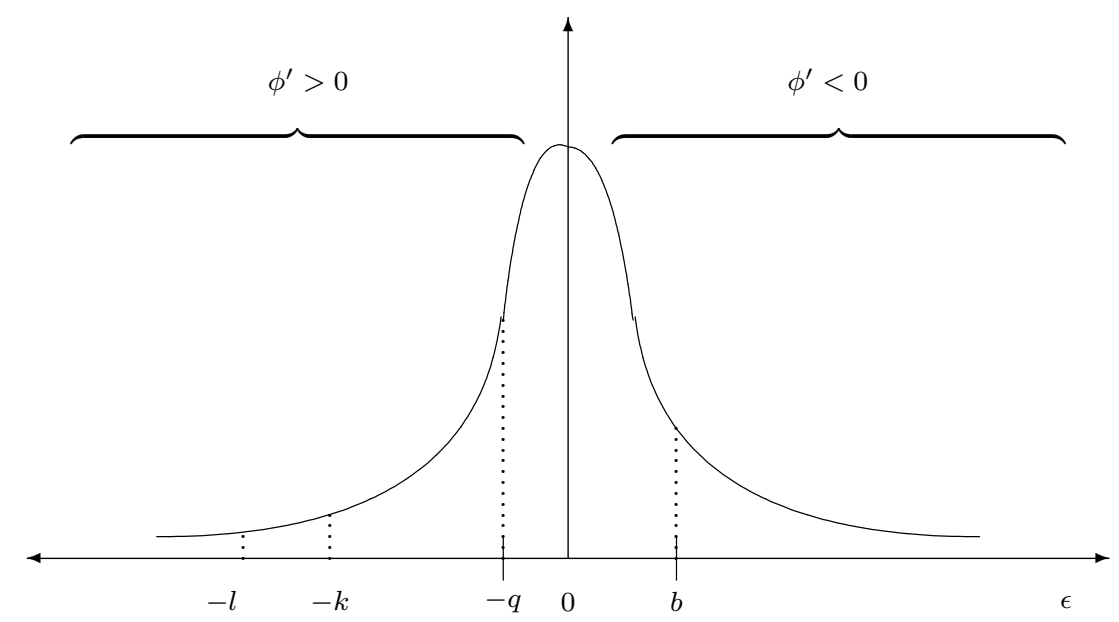

Figure 4: Normal density function. If $-p a+c=-k,-p a=-l$, and $-k<-l<0$, then $\phi(-k)>\phi(-l)$. If $-p a+c=b,-p a=-q$, and $b>q>0$ then $\phi(-q)>\phi(b)$.

Therefore, if $p^{2}[\phi(0)-\phi(c)]<\alpha, E U$ is strictly concave. This, together with $\frac{\partial E U}{\partial a}(0, c, \theta)>0$, means that there is a unique maximizer, $a^{*}$, and that $\frac{\partial E U}{\partial a}\left(a^{*}, c, \theta\right)=0$.

If $p^{2}[\phi(0)-\phi(c)]>\alpha$, then the facts that $\frac{\partial^{3} E U}{\partial a^{3}}<0$ for any $a<\frac{c}{2 p}$ and that $\frac{\partial^{2} E U}{\partial a^{2}}<0$ for any $a \geq \frac{c}{2 p}$ imply that $\frac{\partial^{2} E U}{\partial a^{2}} \geq 0$ only in an interval $[0, u]$, where $u<\frac{c}{2 p}$. In this case, $E U$ would look as depicted in Figure 5. Now, the fact that $\frac{\partial^{2} E U}{\partial a^{2}} \geq 0$ for any $a \leq u$, together with $\frac{\partial E U}{\partial a}(0, c, \theta)>0$, implies that $\frac{\partial E U}{\partial a}(a, c, \theta)>0$ for any $a \leq u$. Thus, there are no maximizers of $E U$ in the interval $[0, u]$. Since $E U$ is strictly concave for $a>u$, it follows that there is a unique maximizer, $a^{*}>u$, and that $\frac{\partial E U}{\partial a}\left(a^{*}, c, \theta\right)=0$. 


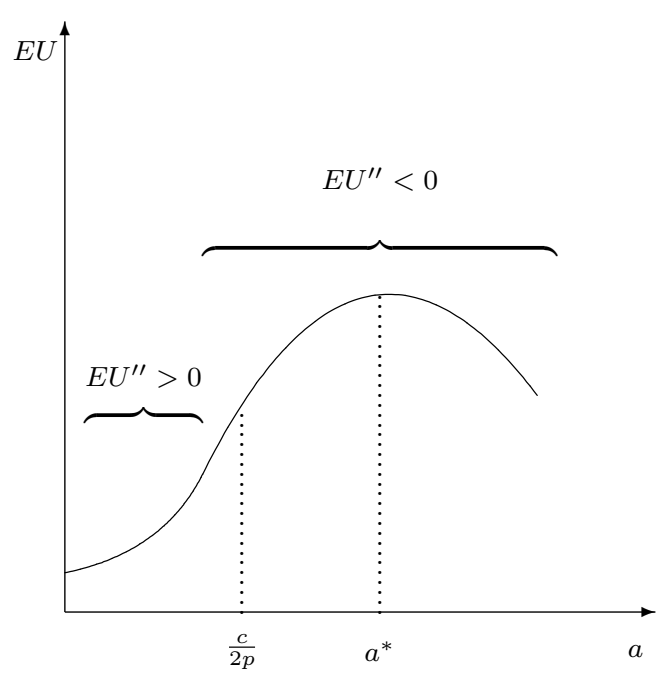

Figure 5: Expected utility function when $-p^{2}[\phi(c)-\phi(0)]-\alpha>0$. 